This item was submitted to Loughborough's Research Repository by the author.

Items in Figshare are protected by copyright, with all rights reserved, unless otherwise indicated.

\title{
Simultaneous spreading and imbibition of blood droplets over porous substrates in the case of partial wetting
}

PLEASE CITE THE PUBLISHED VERSION

http://dx.doi.org/10.1016/j.colsurfa.2015.10.056

\section{PUBLISHER}

(C) Elsevier

VERSION

AM (Accepted Manuscript)

\section{PUBLISHER STATEMENT}

This work is made available according to the conditions of the Creative Commons Attribution-NonCommercialNoDerivatives 4.0 International (CC BY-NC-ND 4.0) licence. Full details of this licence are available at: https://creativecommons.org/licenses/by-nc-nd/4.0/

\section{LICENCE}

CC BY-NC-ND 4.0

\section{REPOSITORY RECORD}

Chao, Tzu-Chieh, Omid Arjmandi-Tash, Diganta Bhusan Das, and Victor Starov. 2019. "Simultaneous Spreading and Imbibition of Blood Droplets over Porous Substrates in the Case of Partial Wetting". figshare. https://hdl.handle.net/2134/19608. 


\section{Simultaneous spreading and imbibition of blood droplets over porous substrates in the case of partial wetting}

Tzu Chieh Chao ${ }^{\text {a }}$, Omid Arjmandi-Tash ${ }^{\text {b }}$, Diganta B. Das ${ }^{c}$, Victor M. Starov ${ }^{{ }^{*}}$ *

Department of Chemical Engineering, Loughborough University, Loughborough, LE11 3TU, UK,

\footnotetext{
a T.Chao@lboro.ac.uk, ${ }^{\mathrm{b}}$ O.Arjmandi-Tash@lboro.ac.uk, ${ }^{\mathrm{c}}$ d.b.das@lboro.ac.uk, d v.m.starov@lboro.ac.uk
}

\section{Abstract}

The sampling process of dried blood spot (DBS) is spreading of blood, which is NonNewtonian fluid, over porous substrates. Spreading/imbibition behaviour of blood samples over Whatman 903 filter paper in complete wetting case has been investigated earlier (Tzu Chieh Chao et al., 2015). The spreading behaviour of DBS sampling has been investigated below in the case of partial wetting. Nitrocellulose membranes (NCM) with different pore size and silanized Whatman 903 blood saving card have been used as porous substrates. The spreading experiments have been applied to obtain the time evolution of spreading parameters, such as, radius of droplet base, dynamic contact angle and radius of the wetted region. The result of spreading on NCM showed that the spreading process was a partial wetting spreading. A separation of red blood cells (RBCs) and blood plasma has been found in the case of the blood drop spreading over 0.2 and $3.0 \mu \mathrm{m}$ NCMs. Important that while the RBCs were not damaged in this process. This opens a completely new opportunity to (1) investigate RBCs and plasma separately; (2) to use this method for non-destructive separation of living cells from aqueous solutions.

Key words: spreading/imbibition, wetting, porous substrate, dried blood spot 


\section{Introduction}

Dried blood spots (DBS) is a high potential blood collecting and sampling method which provides several advantages in blood sample collection, storage and transportation against conventional whole blood collection or plasma collection [1-3]. Recently, DBS method has been widely investigated in multiple aspects and applications, i.e. Therapeutic drug monitoring (TDM), Pharmacokinetic, clinical studies etc. [4-12]. However, there are some disadvantages in the DBS process, such as, unequal distribution, haematocrit effects and analytes extraction, which limited the application of DBS for high sensitive and quality analysis [1,2,4,6,13-15]. Although, new developments and application of DBS have been intensively studied from both experimental and clinical points of view, hydrodynamics of spreading/imbibition of blood in the course of sampling was investigated only recently $[16,17]$.

The principle of DBS application is as follows: using a thin porous substrate, such as cotton fibres, cellulous fibres and polymer membrane etc., as an absorbent sponge where blood droplet from a fingertip or syringe is collected and the blood preserved as a dried spot sample. Therefore, the whole process of DBS sampling could be considered as spreading of non-Newtonian fluid (blood drop) over porous substrate (DBS card) with simultaneous penetration and spreading inside the porous substrate.

The spreading and wetting of porous substrate by blood are complex process depending on the physical and chemical properties of both a substrate and a liquid (blood). Investigations of wetting and spreading of pure Newtonian [18-21] and non-Newtonian liquids [22,23] over smooth homogeneous surfaces have been well documented in the literature. However, the spreading and wetting condition of a drop on a porous substrate are obviously different due to the presence of a porous layer. This process has been investigated 
recently in the case of spreading/imbibition of Newtonian liquids [20,21] and in the case of blood spreading/imbibition $[16,17]$ in the case of complete wetting.

Below influence of hydrophilicity of the porous substrate on blood spreading is investigated. For this purpose spreading of a blood droplet over porous substrate in the case when blood wets only partially the porous substrate is investigated.

Firstly, the difference between a complete wetting and a partial wetting of the porous substrate in the case of spreading/imbibition process is clarified below.

\subsection{Partial wetting case}

The spreading of a droplet over a porous substrate in this case can be subdivided into three stages as schematically shown in Fig. 1a: (1) a relatively fast spreading during the first stage until the radius of the droplet base reaches the maximum value and the contact angle reaches the value of static advancing contact angle; (2) during the second stage the contact line remains fixed at the maximum value but the volume decreases due to loss caused by the imbibition into the porous substrate, while contact angle during this stage decreases from the static advancing contact angle to static receding contact angle; (3) during the third stage of spreading/imbibition the shrinkage of the drop base takes place at constant static receding contact angle until complete disappearance. 


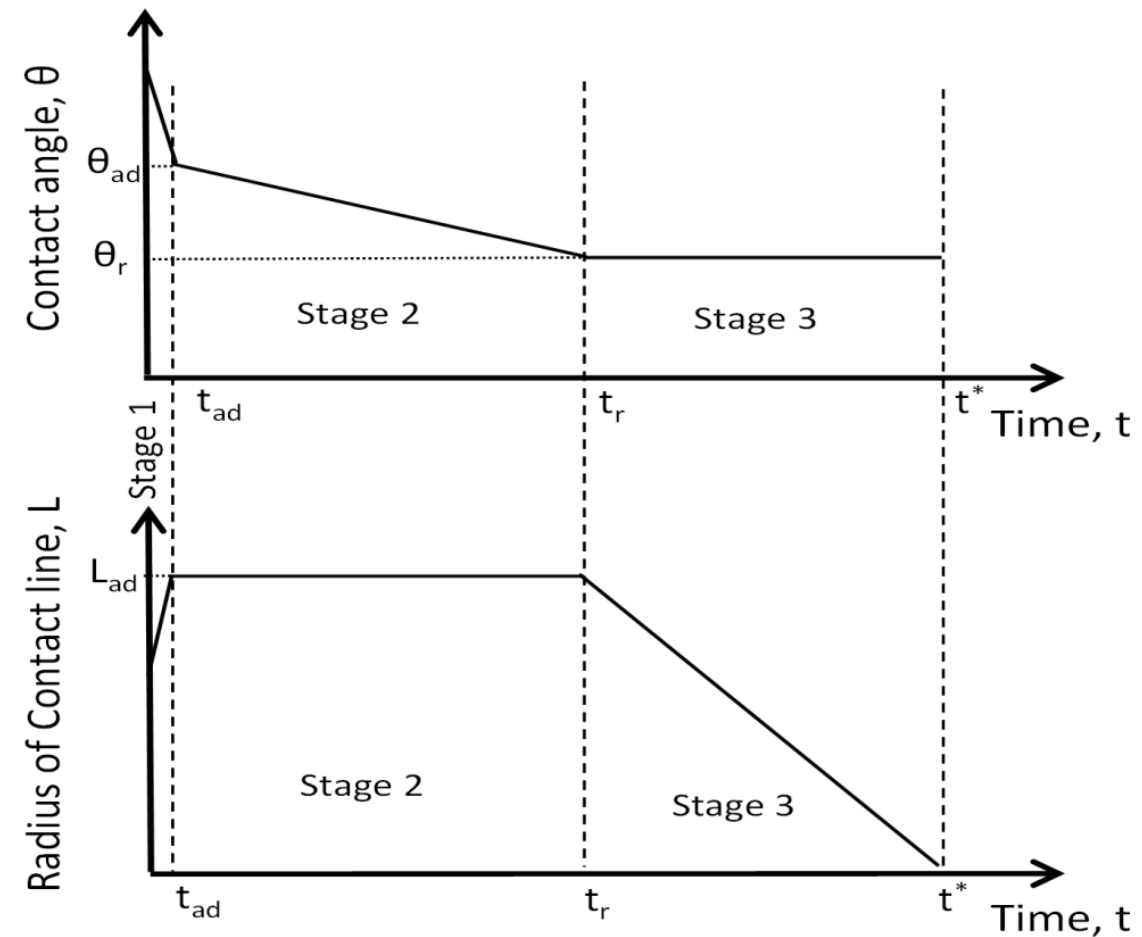

Fig. 1a. Droplet spreading/imbibition over porous substrate in the case of partial wetting: three stages of spreading/imbibition. $L_{a d}$ is the maximum radius of droplet base, $\theta_{\mathrm{ad}}$ is the advancing contact angle, $\mathrm{t}_{\mathrm{ad}}$ is the time when $\theta_{\mathrm{ad}}$ is reached, $\theta_{\mathrm{r}}$ is the receding contact angle, $\mathrm{t}_{\mathrm{r}}$ is the time when $\theta_{\mathrm{r}}$ is reached and $\mathrm{t}^{*}$ is the time when complete imbibition is finished.

The characteristic feature of spreading/imbibition process in the case of partial wetting is the presence of stage 2, when the edge of the droplet is pinned: this is caused by the contact angle hysteresis.

\subsection{Complete wetting case}

In this case there is no contact angle hysteresis and the stage 2 is absent. The spreading process can be subdivided into two stages: (1) a relatively fast spreading case. During this stage radius of the droplet base reaches its maximum value; (2) this stage is followed by stage 3 when the imbibition prevails over the spreading and the radius of the droplet base is shrinking (Fig. 1b). Note, there is no contact angle hysteresis in the case of complete wetting. 
However, over the most part of the stage 3 in the case of complete wetting the contact angle retains the constant value, which has nothing to do with contact angle hysteresis but determined by a pure hydrodynamic reason.

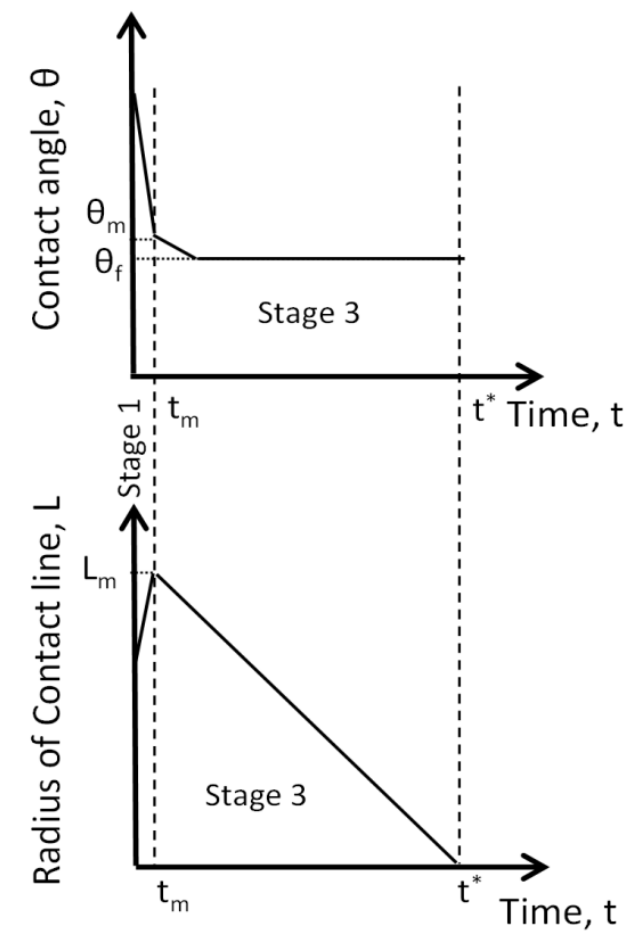

Fig. 1b. Droplet spreading/imbibition over the porous substrate. Complete wetting case: only two stages of spreading/imbibition in this case. $L_{m}$ is the maximum radius of droplet base, $t_{m}$ is the time when $L_{m}$ is reached, $\theta_{\mathrm{m}}$ is the contact angle at $t_{\mathrm{m}}, \mathrm{t}^{*}$ is the time when complete imbibition is finished and $\theta_{\mathrm{f}}$ is the final contact angle at $\mathrm{t}^{*}$. Note, in the case of complete wetting the stage 2 is absent (see Fig. 1a).

Below the spreading behaviour of blood over nitrocellulose membranes with different average pore sizes and treated (hydrophobised) Whatman 903 filter paper is investigated. Due to the similarity of the rheological properties of pig's blood to human blood, such as, blood viscosity, plasma viscosity and others, porcine blood with different haematocrit levels was used below. 


\section{Materials and methods}

The spreading experiments were carried out to monitor time evolution of droplet height,

radius of spreading, dynamic contact angle and radius of the wetted spot. Earlier $[16,17]$ the spreading behaviour of blood on commercial DBS filter paper has been investigated in the case of complete wetting. Below the spreading/imbibition in the case of partial wetting is investigated. For this purpose the nitrocellulose membranes with several different pore sizes and silanized (hydrophobised) Whatman 903 filter paper were used as model porous substrate to investigate the effects of hydrophobicity of the porous substrate on the process. Blood samples with two different haematocrit levels, $30 \%$ and $50 \%$, were used to investigate the effects of haematocrit level in the case of partial wetting.

\subsection{Materials and instruments}

Porcine blood was collected in EDTA anti-coagulated tubes (International Scientific Supplies Ltd. Bradford, UK) from a local butcher and treated to have different haematocrit levels $[16,17]$. The blood samples of two different haematocrit levels, $30 \%$ and $50 \%$ were chosen and used in the spreading experiments. Whatman 903 filter paper (blood saving card) and nitrate cellulose membranes with pore sizes $0.2,3$ and $8 \mu \mathrm{m}$ (marked by the supplier), both provided from GE health care (UK), were used as model porous substrates. The porosity of the Whatman 903 filter paper was in the range of 0.54 to 0.6 and the thickness was $500 \pm$ $25 \mu \mathrm{m}$ measured by SEM. All samples used of nitrocellulose membranes were plane circles of radius $47 \mathrm{~mm}$ and thickness in the range of $105-140 \mu \mathrm{m}$. The porosity of the membrane ranges between 0.66 and 0.84 as provided by the manufacturer.

AVT Pike F-032 high performance camera (Allied Vision Technologies, UK) was used for the top view recording of both porous substrates as well as side views recording of blood spreading over nitrocellulose membrane, and I-Speed high speed camera (Olympus, UK) was used for side view recording on Whatman 903 filter paper. The optical objective used in 
side view experiment for drop spreading was IF-3 standard (INFINITY PHOTO-OPTICAL GmbH, Germany). KRUSS DSA100 and drop shape analysis (KRUSS GmbH, UK) was used to determine the advancing and receding contact angles of blood droplets on all porous substrates used.

\subsection{Silanization of Whatman 903 filter paper}

Silanization is the covering of a surface via self-assembly with organofunctional alkoxysilane molecules to increase the hydrophobicity. Materials containing hydroxyl group, such as glass, metal oxide surface and cotton, can be silanized due to the formation of covalent bonds, which were caused by the hydroxyl groups attacking and replacing the alkoxy groups of the silane. The goal of silanization is to form organic silane layer on the surface of cotton fibers which allows obtaining the porous substrates of the same porosity, however, with higher hydrophobicity.

Whatman 903 filter paper was dried for one hour at $140{ }^{\circ} \mathrm{C}$ and directly placed into a sealed dried temperature chamber with silicone gel to eliminate the effects of the humidity. APTES (3-aminopropyl-triethoxysilane) purchased from Sigma-Aldrich (UK) was poured into Petri dish and placed into the same temperature chamber at $25{ }^{\circ} \mathrm{C}$ for slowly evaporation to silanize the surface of fibers inside Whatman 903 filter paper. Each Whatman 903 paper was silanized for over 48 hours.

\subsection{Spreading experiments: nitrocellulose membranes}




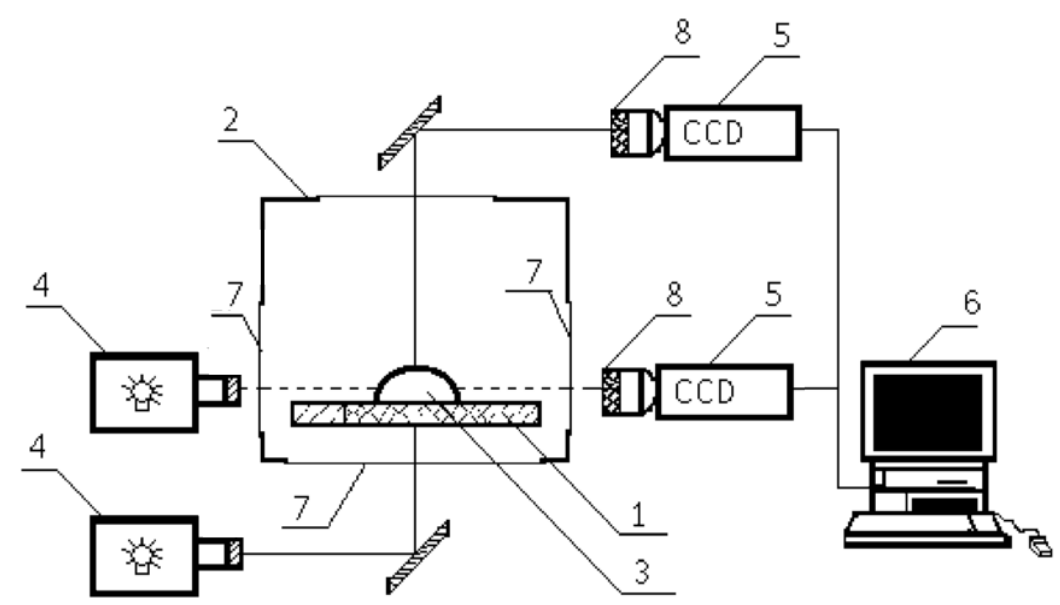

Fig. 2 Sketch of the experimental setup of spreading experiments: 1 - porous substrate; 2 - hermetically closed, thermostated chamber; 3 - liquid drop; 4 - light sources; 5 - CCD cameras; 6 - PC; 7 - optical windows; 8 - optical objectives.

The experimental setup used for spreading experiments is shown in Fig 2, which is the same design as used in [17]. The nitrocellulose membrane was placed in the centre of the environmental chamber to control the temperature and humidity. Silicone gel was placed into the chamber to maintain constant humidity. The environmental chamber was mounted on a vibration-control stand to prevent vibrations. The spreading process of blood drops over porous substrates was recorded and analysis using the top and side views.

In each spreading experiment a constant value of blood droplet volume was produced using $5.00 \pm 0.25 \mu \mathrm{l}$ syringe and placed on the nitrocellulose membrane within less than $1 \mathrm{~mm}$ dropping distant to ensure the consistency of each experimental measurement. The time evolution of volume of blood droplets were measured and calculated using the recorded images for all spreading samples. 


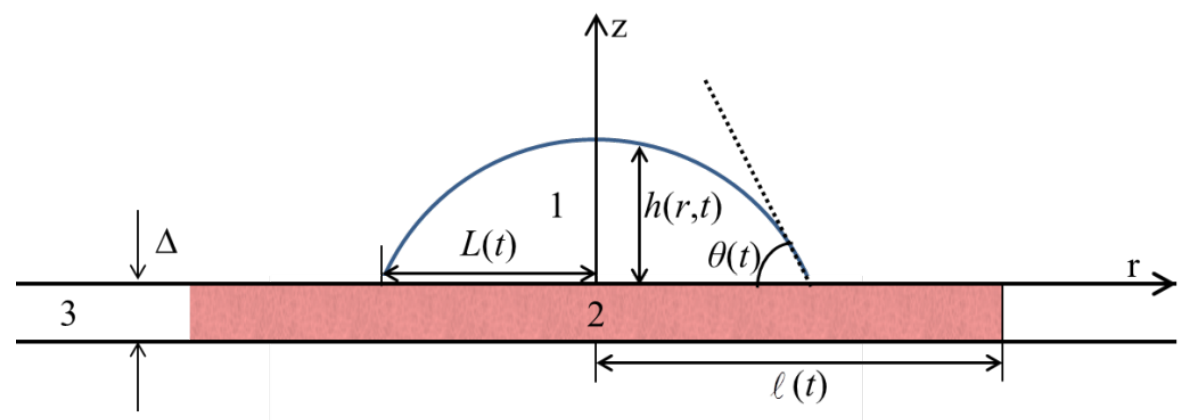

Fig. 3 Cross-section of the axis-symmetric spreading drop over initially dry porous substrate with thickness $\Delta$. 1- liquid drop; 2- wetted region inside the porous substrate; 3- dry region inside the porous substrate. $\mathrm{L}(\mathrm{t})$ - radius of the drop base; $l(t)$ - radius of the wetted area inside the porous substrate; $\Delta$ - thickness of porous substrate; $\theta(t)$ - contact angle; $\mathrm{r}, \mathrm{z}$ coordinate system

Fig. 3 shows the cross-section of the axis-symmetric spreading drop over the porous substrate with thickness $\Delta$. The time evolution of the spreading radius, $L(t)$, and the droplet height, $h(t)$, were monitored using side view camera. The time evolution of wetted region radius, $l(t)$, was recorded using top view camera. For each sample the camera recording started as the blood drop touched the porous surface and finished after the complete penetration of the droplet into the porous substrate. The time evolution of dynamic contact angle was calculated from the experimental result based on spherical shape assumption.

Due to the thin thickness of porous substrate, the cross section of the porous substrate was assumed to be fully saturated as shown in Fig. 3. All experimental data for each porous substrate used were averaged using at least ten repeated spreading experiments.

\subsection{Spreading experiment: silanized Whatman 903 filter paper}

The spreading experiment of un-silanized Whatman 903 filter paper was reported in our previous experimental paper [17]. The experimental setup and method were the same as 
shown in Fig. 2. The treated paper samples were placed into the temperature and humidity controlled chamber at $25{ }^{\circ} \mathrm{C}$ and controlled humidity. Blood samples with $30 \%$ and $50 \%$ haematocrit levels were placed on the porous substrate using $10 \pm 0.5 \mu l$ syringe. The initial volume was calculated and checked for each experimental run. Due to the very short duration of the spreading process of blood spreading/imbibition over Whatman 903 filter paper (less than 0.5 second) I-Speed high speed camera was used to monitor the process. Side view images were recorded at 600 frames per second and the top view images were recorded at 60 frames per second. The time evolution of radius of the droplet base, radius of the wetted region, droplet height and dynamic contact angle were recorded and calculated from the result of both top and side view images.

\subsection{Measurements of static receding and advancing contact angles}

The static receding and advancing contact angles of blood with different haematocrit levels, $30 \%$ and 50\%, were determined using additional experiment on nitrocellulose membranes with the following average pore sizes: 0.2 , 3.0 and $8.0 \mu \mathrm{m}$. Silanized Whatman 903 filter paper showed complete spreading behavior (see Fig. 1b and below). However, in the case of complete wetting there is no hysteresis of contact angle. Because of that measurement of hysteresis contact angles were conducted on nitrocellulose membranes only.

The experimental setup is shown in Fig. 4. The membrane substrate was mounted and fixed on a flat horizontal stand. The blood droplets were pumped in/out the membrane using a syringe pump. The droplet height and radius of the droplet base were measured and the contact angle was calculated using KRUSS DSA 100. Static advancing contact angle was recorded at the time when the base radius of the sessile drop of blood stated to move, which was caused by pumping blood by the syringe. The receding contact angle was determined at 
the moment when the radius of base of sessile drop started to decrease which was caused by the sucking of blood by the syringe pump.[24,25]

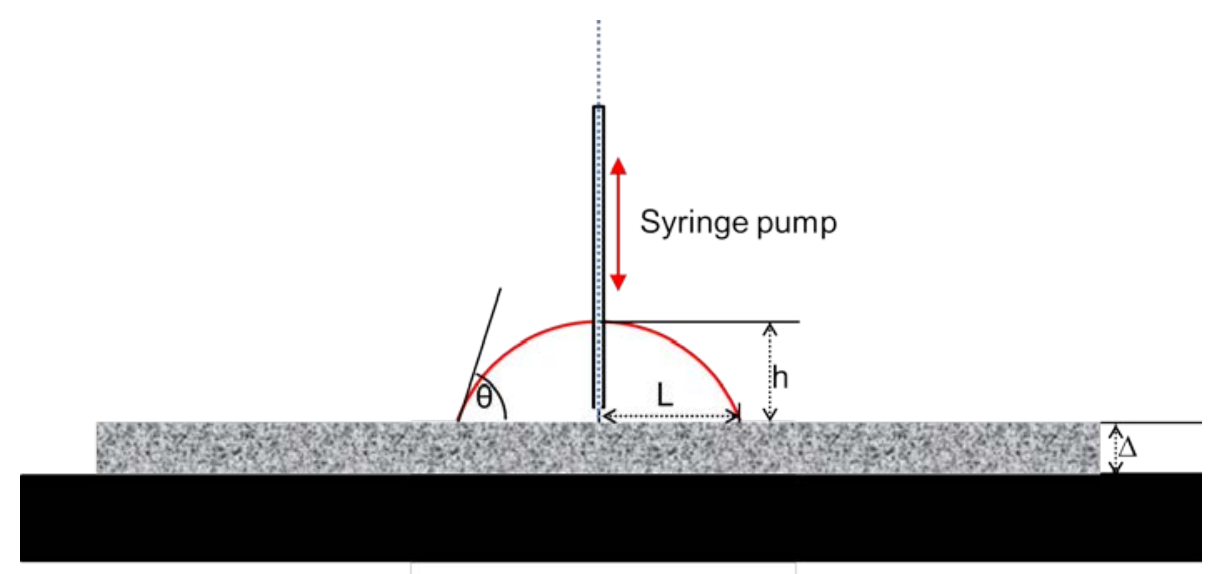

Fig. 4 The diagram of the experimental set up for measurements of static receding and advancing contact angles.

\subsection{Measurements of the permeability of porous substrate}

The permeability of porous substrate and effective capillary pressure are considered as a single coefficient in our previous theoretical model for the complete wetting case [16]. This coefficient was obtained from the permeability experiments based on the modified Darcy’s law. Rectangular sheets of $1.5 \mathrm{~cm} * 6.0 \mathrm{~cm}$ were used. Each sheet was immersed $0.1-0.3 \mathrm{~cm}$ into a blood container and the position of imbibition front was monitored by high speed camera. It was shown earlier that the blood is shear thinning behaviour, which viscosity, $\eta$, is well described by simple power law equation: $\eta=k \dot{\gamma}^{n-1}$, where $\dot{\gamma}$ is applied shear rate, $\mathrm{k}$ is the flow consistency index and $\mathrm{n}$ is the fluid behavior index. According to modified Darcy's law [16], the position of imbibition front can be expressed by following equation:

$$
d^{1+\frac{1}{n}}(t)=\frac{K_{n} P_{c}^{\frac{1}{n}}}{k^{\frac{1}{n}}}(1+1 / n) t
$$


where $d(t)$ is the position of the imbibition front inside the filter paper, $K_{n}$ is the permeability coefficient, and $\mathrm{P}_{\mathrm{c}}$ is the capillary pressure. The value of the coefficient, $\frac{K_{n} P_{c}^{1 / n}}{k^{1 / n}}$, can be determined by the slope of the straight line in the figure of $d(t)$ against $t$. The measured values of $\frac{K_{n} P_{c}^{1 / n}}{k^{1 / n}}$ are presented in the Table 1.

Table 1. The value of $\frac{K_{n} P_{c}^{\frac{1}{n}}}{k^{\frac{1}{n}}}$ for $30 \%$ and $50 \%$ hct blood on silanized Whatman 903 paper

\begin{tabular}{|l|l|}
\hline Hct levels (\%) & $\frac{K_{n} P_{c}^{\frac{1}{n}}}{k^{\frac{1}{n}}}\left(\mathrm{~mm}^{(1+1 / \mathrm{n})} \mathrm{s}^{-1}\right)$ \\
\hline 30 & 117.15 \\
\hline 50 & 30.184 \\
\hline
\end{tabular}

\section{Results and discussion}

\subsection{Spreading experiment}

Note that the size of RBCs is around $\sim 4 \mu \mathrm{m}$. That is only plasma can penetrate into pores of nitrocellulose membranes with 0.2 and $3.0 \mu \mathrm{m}$ pores; but both plasma and RBCs penetrate into pores of $8 \mu \mathrm{m}$ membrane and Whatman 903 filter papers. There is a significant different between the kinetics of spreading over two different types of porous substrates used. The total duration of the spreading process of $10 \mu \mathrm{l}$ sample over silanized Whatman 903 filter paper was around 0.3 second for $30 \%$ haematocrit level and 0.47 second for $50 \%$ haematocrit level. It was also found that in spite of silanization the Whatman 903 filter paper still showed the complete wetting behaviour (see Fig. 1b).

However, the spreading time over nitrocellulose membrane was up to 20 second for $30 \%$ haematocrit level and 180 second for 50\% haematocrit level over the membrane with $8 \mu \mathrm{m}$ 
pore size. There was also a substantial different in the spreading behaviour of blood on nitrocellulose membrane with different pore sizes beside the spreading time difference between the two different porous materials used. Time evolutions of base radius of blood drop over two different porous substrates are shown in Figs. 5 and 6. Fig. 5 presents the results of time evolution of radius of droplet base over nitrocellulose membranes. The dependences presented in Fig. 5a prove that the whole spreading process on the $8.0 \mu \mathrm{m}$ membrane can be subdivided into three stages, as shown earlier (see Fig.1a), which is a characteristic feature of the partial wetting case. During the fast first stage drop spread until the maximum radius, $L_{a d}$, was reached; after that the second stage began where the radius of the droplet base was pinned at the maximum position; and finally, during the third stage the drop radius began to shrink. During the third stage the contact angle remains at the constant value equaled to the static receding contact angle until the complete imbibition of the blood droplet (see Fig. 9). Therefore, blood drop spreading/imbibition over nitrocellulose membranes was a partial wetting process. Note, the pore size of the $8.0 \mu \mathrm{m}$ membrane was bigger than the size of RBCs, which means, both plasma and RBCs penetrated into the membrane.

The time evolution of radius of droplet base on 0.2 and $3.0 \mu \mathrm{m}$ membranes shown in Fig. 5b proceeded much faster as compared with $8.0 \mu \mathrm{m}$ membrane in spite both cases were partial wetting. The difference is caused by smaller pore sizes of 0.2 and $3.0 \mu \mathrm{m}$ membranes: RBCs did not penetrate into the membrane pores and only plasma did. However, the plasma viscosity is much lower as compared with mixture of plasma and RBCs as in the case of 8.0 $\mu \mathrm{m}$ membrane. It was the reason why spreading over 0.2 and $3.0 \mu \mathrm{m}$ membranes was considerably faster than over $8.0 \mu \mathrm{m}$ membrane (Fig. 5).

In all our spreading experiment the drops spreading over silanized Whatman 903 filter paper and nitrocellulose membranes with different pore size remained spherical shape over 
the entire duration of spreading. The spherical cap shape allowed calculating the dynamic contact angle of each droplet using the droplet radius base and height according to wellknown equations [17].

In the case of spreading over 0.2 and $3.0 \mu \mathrm{m}$ pore size nitrocellulose membranes the RBCs did not penetrate inside the membrane pores. That is, the droplet did not penetrate completely into the membrane pores and the final radius of the droplet base did not vanish (Fig. 5b): only stages 1 and 2 are present in this case. 

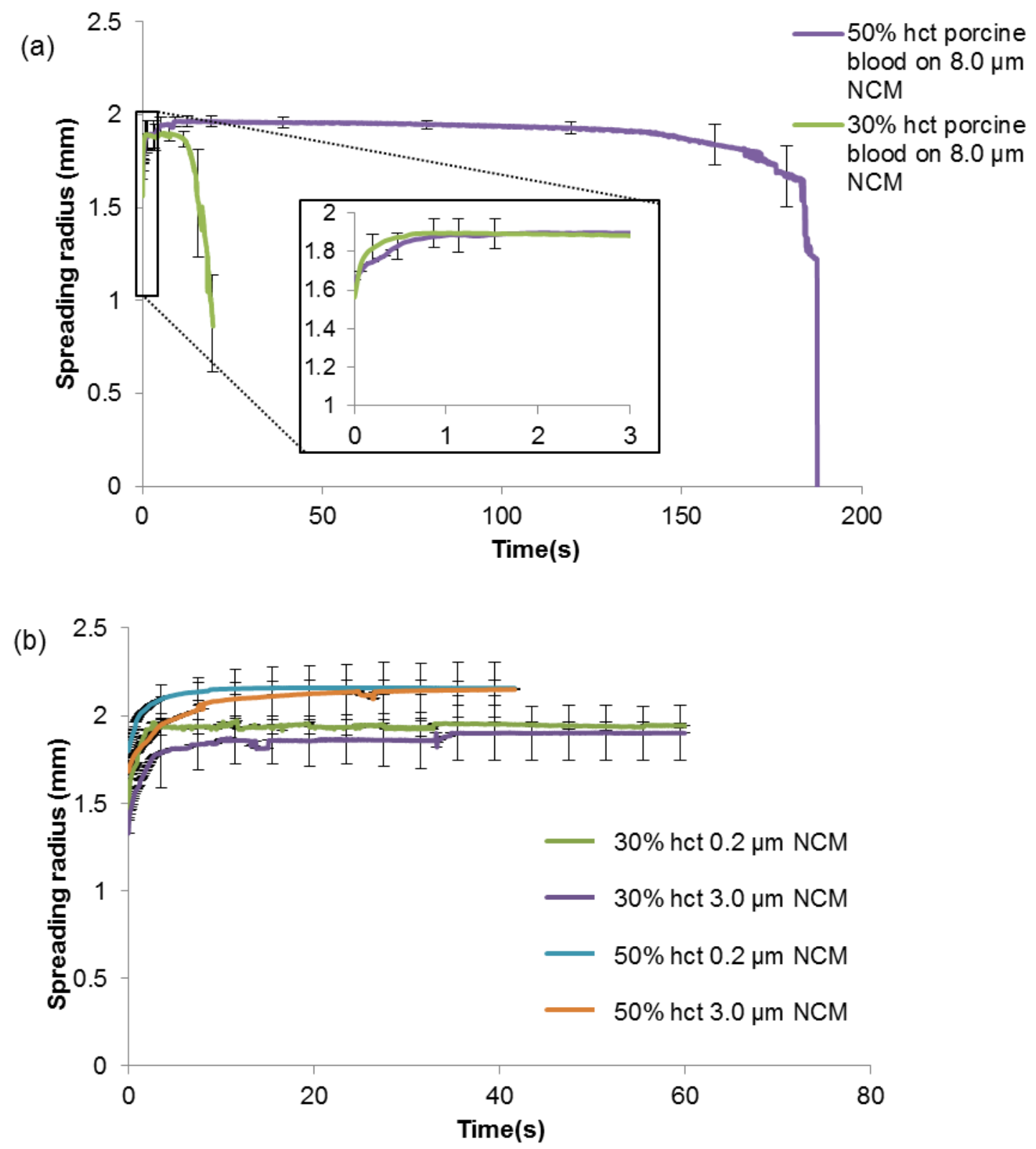

Fig. 5 The time evolution of radius of droplet base of $30 \%$ and $50 \%$ haematocrit level over 0.2, 3.0 and $8.0 \mu \mathrm{m}$ pore size nitrocellulose membranes. (a) spreading over $8.0 \mu \mathrm{m}$ pore size nitrocellulose membrane. Insert: magnification of the first stage of spreading (b) spreading over 0.2 and $3.0 \mu \mathrm{m}$ pore size nitrocellulose membranes.

Situation is completely different in the case of spreading of blood droplets over silanized Whatman 903 filter paper (Fig. 6): in spite of silanization of Whatman 903 filter paper it still showed a complete wetting behavior (compare Fig. 6 and Fig. 1b). However, the dynamic 
contact angels in the course of spreading on silanized filter paper were higher as compared with un-treated filter paper (see below).

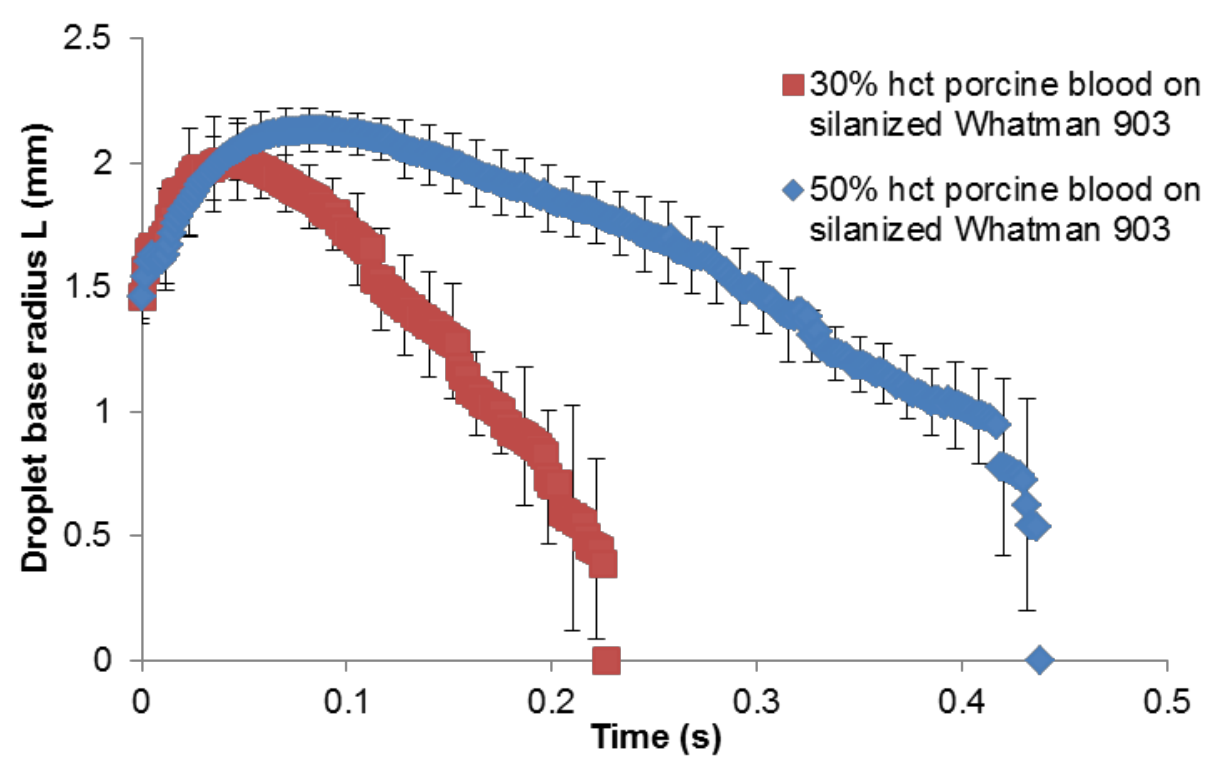

Fig. 6 The time evolution of droplet base radius at 30\% and 50\% haematocrit level over silanized Whatman 903 filter paper. In both cases complete wetting behavior takes place (compare with Fig. 1b)

The edge of the wetted region inside the porous layer was always a circle for all membrane used, except for the blood samples spreading over the $3 \mu \mathrm{m}$ membrane, where the shape of wetted area became irregular.

Our results proved that only plasma and very few RBCs penetrated into the porous membrane in the case of the blood drop spreading over 0.2 and $3.0 \mu \mathrm{m}$ nitrocellulose membranes. This opens a new possibility of blood sampling, when the RBCs are mostly collected on the membrane surface and almost completely separated from plasma, which is collected inside the membrane pores. Important to emphasize that in the course of spreading over 0.2 and $3.0 \mu \mathrm{m}$ nitrocellulose membranes the red bold cells were not damaged. This 
opens a completely new opportunity to (1) investigate RBCs and plasma separately; (2) to use this method for non-destructive separation of living cells from aqueous solutions.

Completely different blood spreading/imbibition occurred in the case of nitrocellulose membrane with $8 \mu \mathrm{m}$ pores. In this case both plasma and red blood cell penetrated into the membrane. A considerable separation of RBCs and plasma occurred inside the membrane during the spreading/imbibition process of blood on $8 \mu \mathrm{m}$ membrane. According to top view images there was a separation of two fronts inside the porous membrane in this case: the outer region of the blood spot was much more transparent and the inner region was denser red colour. The latter means that plasma penetrated faster as compared with RBCs. The whole penetration process can be separated into two stages: during the first stage after the blood droplet deposition the wetted region inside the membrane started to increase and formed two different penetrating fronts. The spreading rate of the outer front of the wetted spot (plasma) was considerably faster compared with the inner front (plasma and RBCs) until the droplet fully penetrated and absorbed into the membrane. In the end of this stage, the increase of outer front slowed down and stopped after all. After that the outer edge of the wetted spot did not expanded any more. After that the second stage started; the inner front continued to increase until it reached the edge of the outer region and completely occupied the whole wetted region. The total duration of the second stage was around 10-15 minutes. These finding are interesting by themselves and probably can be used in the future sampling procedure.

However, there is no noticeable separation of RBCs and plasma in the case of spreading of blood on silanized Whatman 903 filter paper. 
3.2 Dimensionless variables and plots: The time evolution of radius of droplet base of $30 \%$ and 50\% haematocrit level over 0.2, 3.0 and $8.0 \mu \mathrm{m}$ pore size nitrocellulose membranes

In the case of partial wetting, contact angle hysteresis is the most important feature: in the presence of contact angle hysteresis the spreading/imbibition of a sessile droplet goes through three consequent stages (Figs. 1a and 5a). First spreading stage: During this short stage immediately after a deposition the contact angle changes simultaneously reaching in the end values $\theta_{a d}$, which is a static advancing contact angle. Stage two of spreading/imbibition: The contact angle decreases from static advancing contact angle, $\theta_{a d}$, down to static receding contact angle, $\theta_{r}$, at constant radius of the droplet base, $L=L_{a d}$. Stage three of spreading/imbibition: Contact angle remains constant and equal to the static receding value, $\theta_{r}$, while the radius of the droplet base, $L$, decreases until zero value (complete disappearance of the droplet).

The advancing and receding contact angles were obtained from our contact angle experiments as described above and listed in the Table 2.

Note, that in the case of membranes with 0.2 and $3 \mu \mathrm{m}$ pores, RBCs do not penetrate into the membrane pores. That is, in spite of partial wetting, the spreading process proceed differently from NCM with $8 \mu \mathrm{m}$ pores: only first and second stage take place and the contact angle remained almost constant during the measurements after the first stage.

In order to compare the spreading behaviour of blood on different nitrocellulose membranes, the dimensionless parameters were used below to compare the spreading behaviour on different time scales.

For radius of droplet base, radius of wetted region, contact angle and time the following dimensionless values are used below:

$\bar{L}=L(t) / L_{a d}$,

$\bar{l}=l(t) / l^{*}$, 
$\bar{\theta}=\theta(t) / \theta_{a d}$,

$\bar{t}=t / t^{*}$,

where $L_{a d}$ is the maximum radius of droplet base, $l^{*}$ is the radius of wetted region at the end of the process, $\mathrm{t}^{*}$ is the time when complete imbibition is finished (see Fig. 1a). All corresponding parameters are shown in Table 2.

Table 2 Experimental parameters used in Eqs (2-5) for experiment data of spreading over nitrocellulose membranes

\begin{tabular}{|c|c|c|c|c|c|c|}
\hline & $\begin{array}{c}\text { tad } \\
\text { (s) } \\
\text { Time of } \\
\text { reaching } \\
\text { maximum } \\
\text { spreading } \\
\text { radius }\end{array}$ & $\begin{array}{c}\text { t* } \\
\text { (s) } \\
\text { Time of end } \\
\text { of spreading } \\
\text { process }\end{array}$ & $\begin{array}{c}\text { L } L_{\text {ad }} \\
\text { (mm) } \\
\text { Maximum } \\
\text { spreading } \\
\text { radius of } \\
\text { droplet base }\end{array}$ & $\begin{array}{c}\theta_{a d} \\
\text { (degree) } \\
\text { Advancing } \\
\text { contact } \\
\text { angle }\end{array}$ & $\begin{array}{c}\theta_{r} \text { (degree) } \\
\text { receding } \\
\text { contact } \\
\text { angle }\end{array}$ & $\begin{array}{l}\ell^{*}(\mathrm{~mm}) \\
\text { Maximu } \\
\text { m radius } \\
\text { of } \\
\text { wetting } \\
\text { region }\end{array}$ \\
\hline $\begin{array}{c}0.2 \mu \mathrm{m} \\
30 \% \\
\text { blood }\end{array}$ & 11.733 & 49.2 & $1.97 \pm 0.04$ & $44.03 \pm 0.9$ & $22.60 \pm 1.53$ & 3.07 \\
\hline $\begin{array}{c}0.2 \mu \mathrm{m} \\
50 \% \\
\text { blood }\end{array}$ & 19.933 & 52.2 & $2.16 \pm 0.04$ & $45.84 \pm 2.4$ & $24.21 \pm 3.50$ & 2.6 \\
\hline $\begin{array}{c}3.0 \mu \mathrm{m} \\
30 \% \\
\text { blood }\end{array}$ & 11 & N/A & $1.87 \pm 0.13$ & $40.73 \pm 1.57$ & $25.34 \pm 0.77$ & N/A \\
\hline
\end{tabular}




\begin{tabular}{|c|c|c|c|c|c|c|}
\hline $\begin{array}{c}3.0 \mu \mathrm{m} \\
50 \%\end{array}$ & 41.3 & N/A & $2.150 \pm 0.15$ & $46.58 \pm 4.35$ & $25.43 \pm 1.28$ & N/A \\
blood & & & & & \\
\hline $8.0 \mu \mathrm{m}$ & 0.866 & $21.2 \pm 1.9$ & $1.99 \pm 0.07$ & $39.82 \pm 0.517$ & $15.58 \pm 4.09$ & 3.88 \\
$30 \%$ & & & & & & \\
\hline blood & & & & & & \\
\hline $5.0 \% \mathrm{~m}$ & 8.466 & $182.3 \pm 13.3$ & $1.88 \pm 0.06$ & $39.10 \pm 0.44$ & $17.10 \pm 5.10$ & 3.32 \\
blood & & & & & & \\
\hline
\end{tabular}

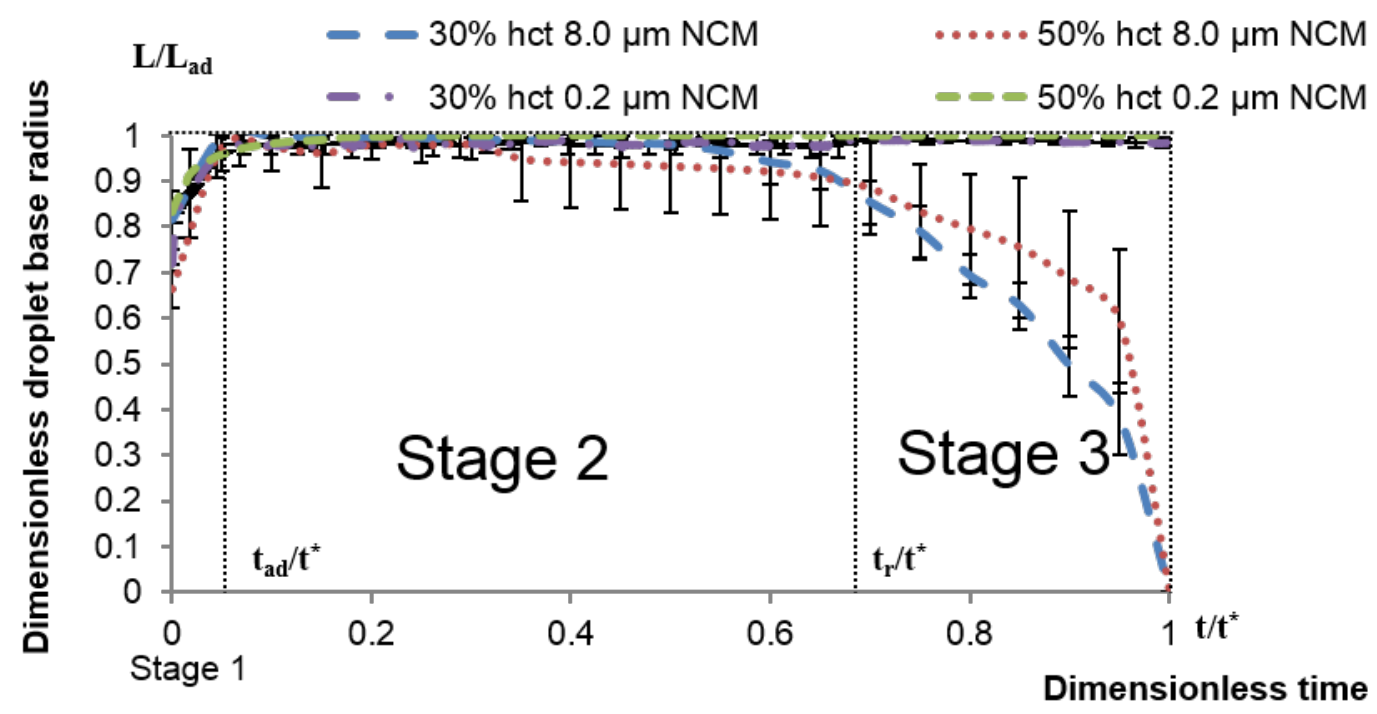

Fig. 7. Dimensionless radius of the droplet base in the case of spreading over nitrocellulose membrane. The case of $3 \mu \mathrm{m}$ pore size membrane is not presented because the instability of the edge of the wetted area. In the case of $0.2 \mu \mathrm{m}$ NCM, only stage 1 and 2 are present. 
Fig. 7 shows a substantial difference in behavior of droplets on $8 \mu \mathrm{m}$ pore size nitrocellulose membrane, where RBCs penetrated into the membrane pores and membranes with smaller pores $(0.2 \mu \mathrm{m})$, where the RBCs did not penetrated into the membrane pores. Spreading on $8 \mu \mathrm{m}$ pores membrane shows a universal behavior independent of haematocrit level (within experimental error).

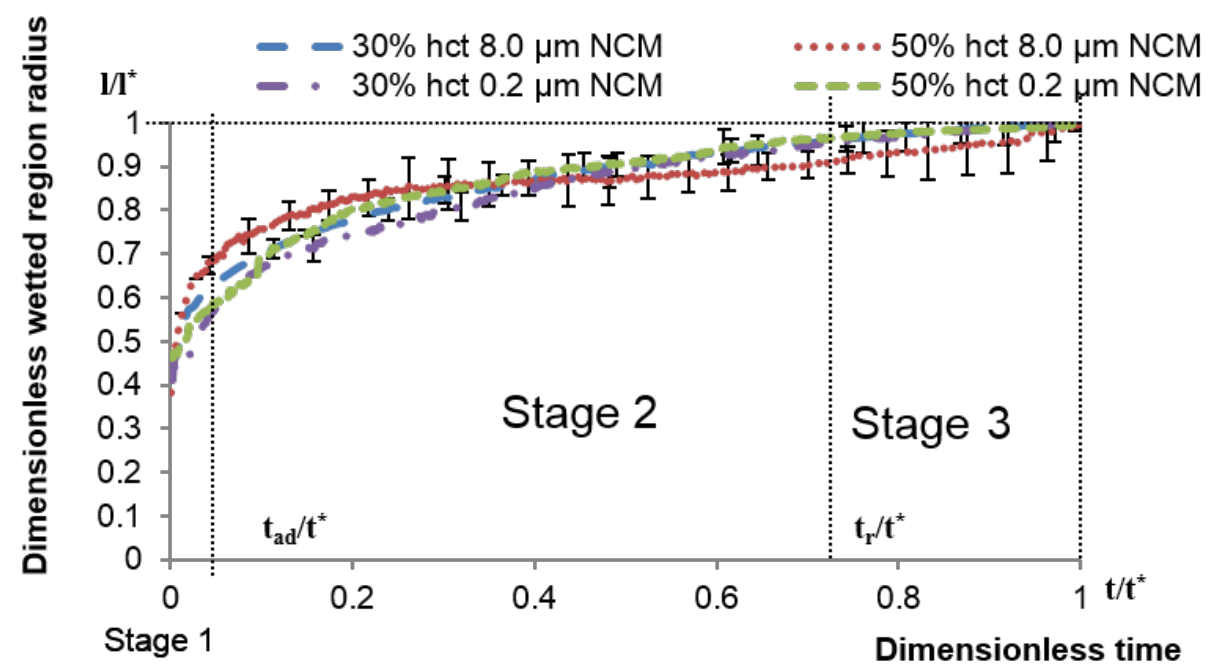

Fig. 8. Dimensionless radius of the wetter area inside the membrane. The case of $3 \mu \mathrm{m}$ pore size membrane is not presented because the instability of the edge of the wetted area, Note, in the case of $0.2 \mu \mathrm{m}$ NCM, stage 3 is only continuation of stage 2 .

Fig. 8 shows that in spite of substantial difference in the spreading behavior of blood droplets on different nitrocellulose membranes (see Fig. 5 and 7) the radius of the wetted area shows a universal behaviour in dimensionless co-ordinates (within experimental error). 


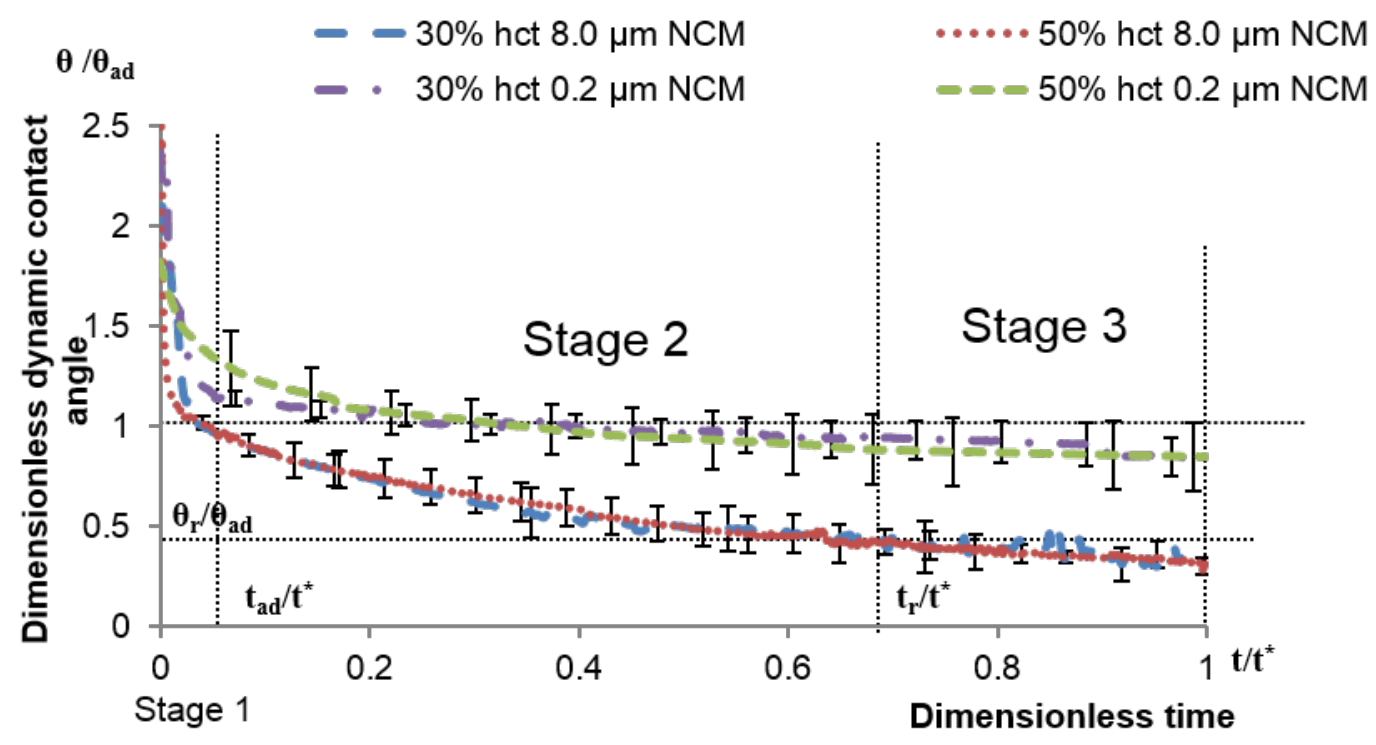

Fig. 9. Dimensionless radius of contact angle in the case of spreading over nitrocellulose membrane. The case of $3 \mu \mathrm{m}$ pore size membrane is not presented because the instability of the edge of the wetted area. Note, in the case of $0.2 \mu \mathrm{m}$ NCM. There is no stage 3 , it is a continuation of stage 2 . The contact angle remained almost constant value after stage 1 .

In Fig. 9 time evolution of the dynamic contact angle in the course of spreading is shown. Dependences of the dynamic contact angle show two different types of universal behavior: for membrane with pores bigger than the size of RBCs, that is $8 \mu \mathrm{m}$, and membranes with smaller pores, where the RBCs did no penetrate $(0.2$ and $3 \mu \mathrm{m})$. In the case of $8 \mu \mathrm{m}$ NCM, the contact angle is equal to the measured earlier receding contact angle, while for $0.2 \mu \mathrm{m}$ NCM the contact angle remained almost equal to advancing contact angle after stage 1. 
3.3 Dimensionless variables and plots: The time evolution of radius of droplet base of 30\% and 50\% haematocrit level over silanized Whatman 903 filter paper.

In this case the blood droplet showed a complete wetting behaviour (Figs. 1b and 6) in spite of hydrophobisation of the filter paper. Hence, a universal behaviour observed and described earlier $[16,17]$ is expected.

In this case the following dimensionless variables were used as in $[16,17]$ :

$\bar{L}=L(t) / L_{m}$,

$\bar{l}=l(t) / l^{*}$,

$\bar{\theta}=\theta(t) / \theta_{m}$,

$\bar{t}=t / t^{*}$,

where $L_{m}$ is the maximum radius of droplet base, $l^{*}$ is the radius of wetted region at the end of the process, $\mathrm{t}^{*}$ is the time when complete imbibition is finished (see Fig. 1b). However, in this case as in [16] all relevant parameters, $L_{m}, \mathrm{l}^{*}, \mathrm{t}^{*}, \theta_{\mathrm{m}}$, are calculated in the same way as in [16] and shown in Table 3.

Table 3 The experiment data of spreading over silanized Whatman 903

\begin{tabular}{|c|c|c|c|c|c|}
\hline & $\begin{array}{c}t_{m \exp } \\
\text { (s) } \\
\text { Time of } \\
\text { reaching } \\
\text { maximum } \\
\text { spreading } \\
\text { radius }\end{array}$ & $\begin{array}{c}t_{\text {exp }} * \\
(\mathrm{~s}) \\
\text { Time of } \\
\text { complete } \\
\text { imbibition }\end{array}$ & $\begin{array}{c}L_{\text {m,exp }} \\
(\mathrm{mm}) \\
\text { Maximum } \\
\text { spreading } \\
\text { radius of } \\
\text { droplet } \\
\text { base }\end{array}$ & $\begin{array}{c}\theta_{m} \\
\text { (degree) } \\
\text { contact } \\
\text { angle at } \\
\text { maximum } \\
\text { spreading } \\
\text { radius }\end{array}$ & $\begin{array}{c}l_{\text {exp }}^{*}(\mathrm{~mm}) \\
\text { Maximum } \\
\text { radius of } \\
\text { wetting } \\
\text { region }\end{array}$ \\
\hline $30 \%$ hct & 0.038 & 0.226 & $2.00 \pm 0.15$ & $40.45 \pm 3.57$ & $2.97 \pm 0.07$ \\
\hline
\end{tabular}




\begin{tabular}{|c|c|c|c|c|c|}
\hline Silanized & & \pm 0.032 & & & \\
\hline $50 \%$ hct & \multirow{2}{*}{0.081} & 0.438 & $2.13 \pm 0.21$ & $39.4 \pm 7.6$ & $2.94 \pm 0.03$ \\
silanized & & \pm 0.021 & & & \\
\hline $30 \%$ hct & 0.05 & 0.351 & $2.18 \pm 0.07$ & $32.80 \pm 1.88$ & $3.36 \pm 0.09$ \\
non-treated & & \pm 0.014 & & & $3.32 \pm 0.06$ \\
\hline no\% hct & 0.075 & 0.508 & $2.18 \pm 0.08$ & $30.94 \pm 2.50$ & \\
\hline
\end{tabular}

Table 3 shows that the main difference between the silanized and non-treated filter papers is the value of contact angle, $\theta_{\mathrm{m}}$, which are substantially higher in the case of silanized filter paper as compared with non-treated filter paper. This was the influence of silanization (hydrophobisation) of the filter paper.

The maximum radius of wetting region can be determined according to the mass conservation law,

$l^{*}=\left(\frac{V_{0}}{\pi m \Delta}\right)$,

where $\mathrm{V}_{0}$ is initial droplet volume, $\mathrm{m}$ is porosity of the porous substrate; $\Delta$ is the thickness of porous substrate. All three $\mathrm{V}_{0}, \mathrm{~m}$ and $\Delta$ were directly measured in [16]. The complete imbibition time can also be determined based on our adoption of the characteristic time, $t_{p}^{*}$ [16]:

$t^{*}=v t_{p}^{*}$, 
where the $v$ is an almost universal numerical parameter, which is around $\sim 0.24 \pm 0.04$ and $t_{p}^{*}$ is the characteristic time scale, $t_{p}^{*}=\frac{l^{*(1+1 / n)} k^{1 / n}}{K_{n} P_{c}^{1 / n}}$, which depends on the value of the coefficient of permeability and capillary pressure as shown in Table 1. [17]

Due to the fast expansion of the blood spreading, the equation of droplet spreading, the maximum droplet base radius, $\mathrm{L}_{\mathrm{m}}$, can be approximately approached by the following equation from the model of droplet spreading over saturated porous layer [26]:

$L_{m}=\left[\frac{n}{2 n+1} \frac{\lambda}{\alpha}\left(\frac{\sigma}{k}\right)^{1 / n} \frac{V_{0}^{(n+2) / n}}{(2 \pi)^{(n+2) / n}} t^{*}\left(\overline{t_{m}}+\overline{t_{0}}\right)\right]^{\alpha}$,

where $\sigma$ is the surface tension of blood and $t_{0}$ is the duration of initial stage which is close to zero; $\alpha=\frac{n}{3 n+7} ; \lambda$ is a constant, which has been determined in [27]. The value of each parameters used in theoretical prediction is the same as in [16]. As for the contact angle $\theta_{\mathrm{m}}$, the value of simulated prediction can be obtained from the following equation:

$$
\theta_{m}=\frac{4 V_{0}}{\pi L_{m}^{3}}\left(1-\bar{l}_{m}^{2}\right)
$$

The calculated prediction of $t^{*}, l^{*}, L_{m}$ and $\theta_{m}$ for silanized filter paper using the simulated result and the coefficient of permeability and capillary pressure from additional experiment (Table 1) are presented in Table 4. The result of calculated parameters shows a good agreement as compared with our experiment observations (Table 3), which indicates that our complete wetting model is also applicable for the spreading process on silanized filter paper. 
Table 4 The calculated value of theoretical prediction of spreading parameters on silanized Whatman 903 filter paper.

\begin{tabular}{|c|c|c|c|c|}
\hline Hct level (\%) & $\mathrm{t}_{\text {sim }}^{*}(\mathrm{~s})$ & $\mathrm{l}^{*}{ }_{\text {sim }}(\mathrm{mm})$ & $\mathrm{L}_{\text {sim }}^{*}(\mathrm{~mm})$ & $\theta_{\mathrm{m}, \mathrm{sim}}\left(^{\circ}\right)$ \\
& $\begin{array}{c}\text { Time of } \\
\text { complete }\end{array}$ & Maximum & Maximum & Contact angle at \\
& rimbibition & wetted region & spreading radius & maximum \\
& $0.17 \pm 0.04$ & $3.34 \pm 0.24$ & $1.95 \pm 0.05$ & $51.16 \pm 4.04$ \\
\hline 30 & $0.72 \pm 0.17$ & $3.34 \pm 0.24$ & $1.95 \pm 0.05$ & $50.39 \pm 3.99$ \\
\hline 50 & & & & \\
\hline
\end{tabular}

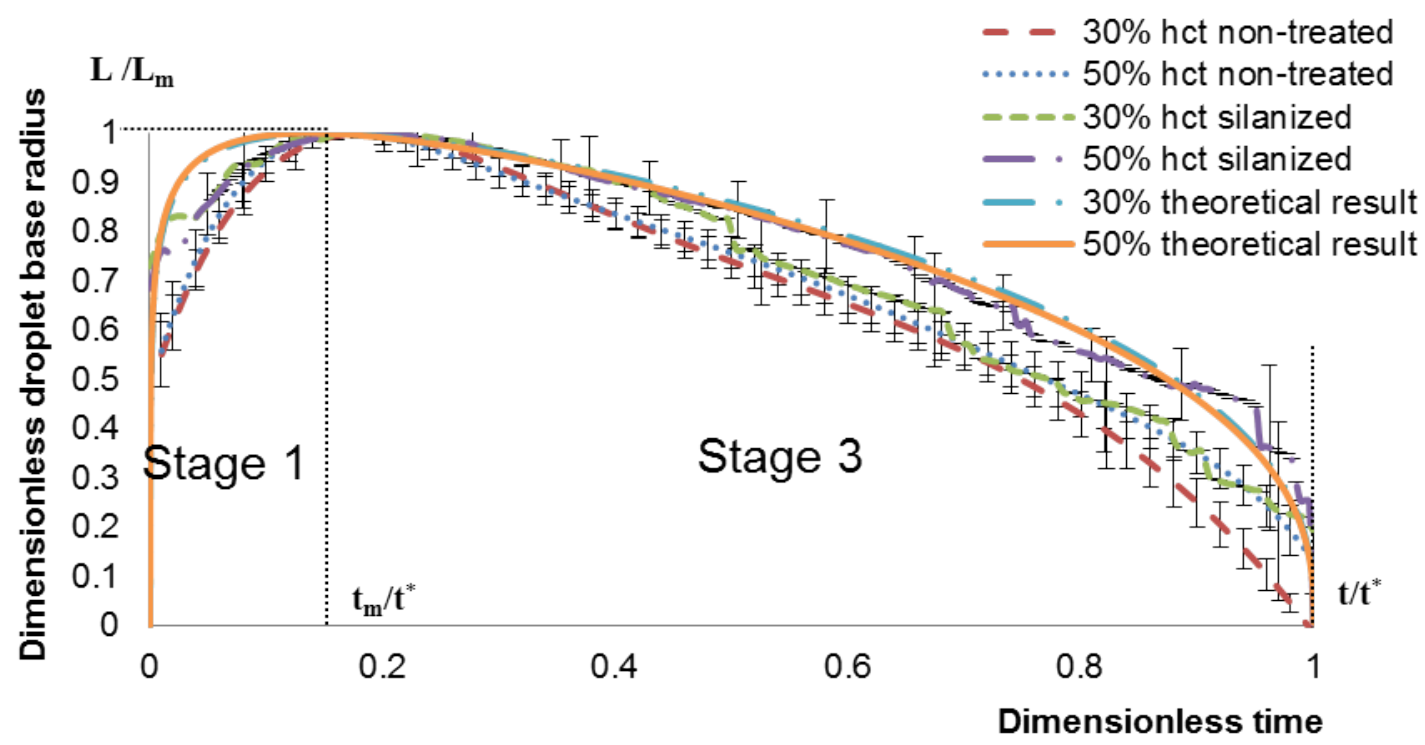

Fig. 10. Dimensionless radius of the droplet base in the case of spreading over silanized and non-treated Whatman 903 paper. 


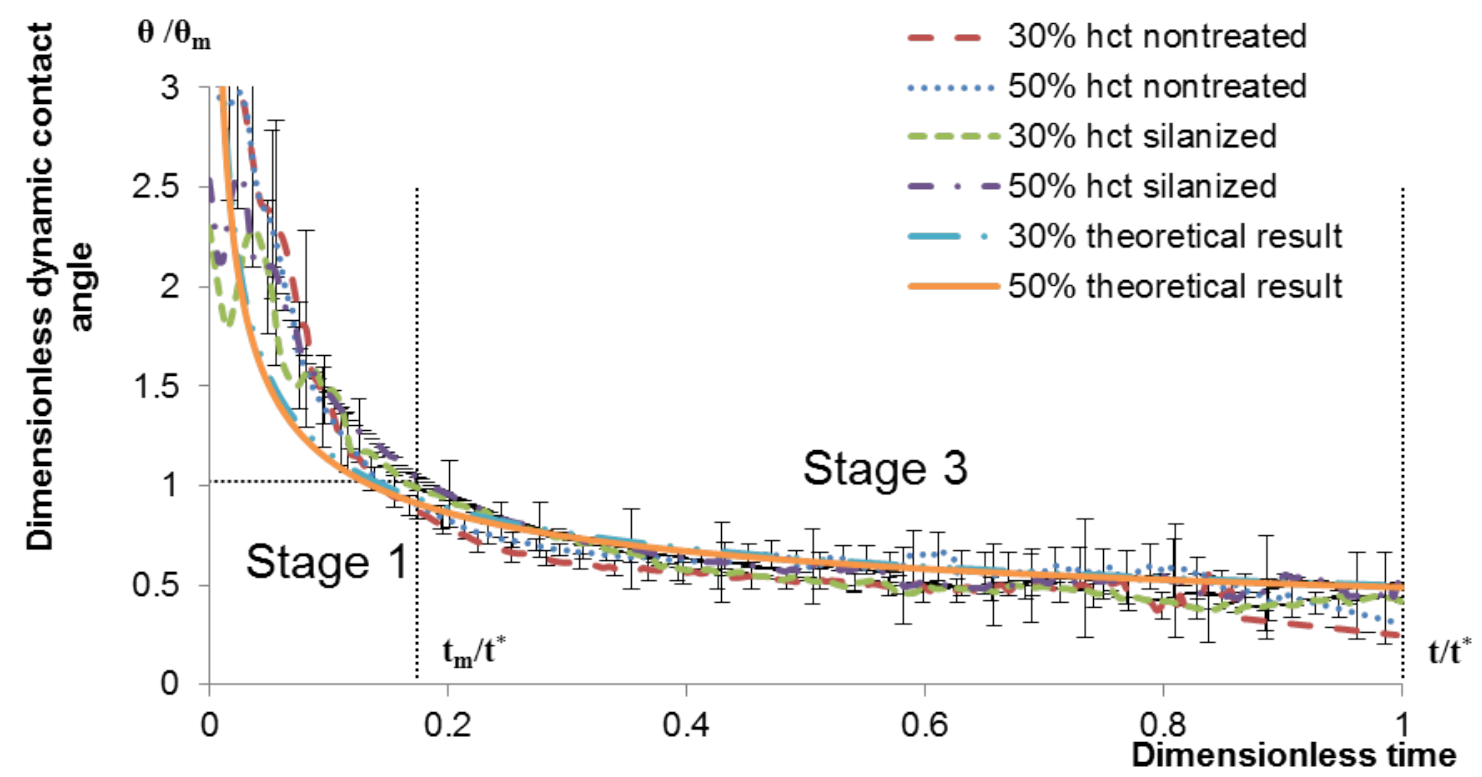

Fig. 11. Dimensionless dynamic contact angle in the case of spreading over silanized and non-treated Whatman 903 paper.

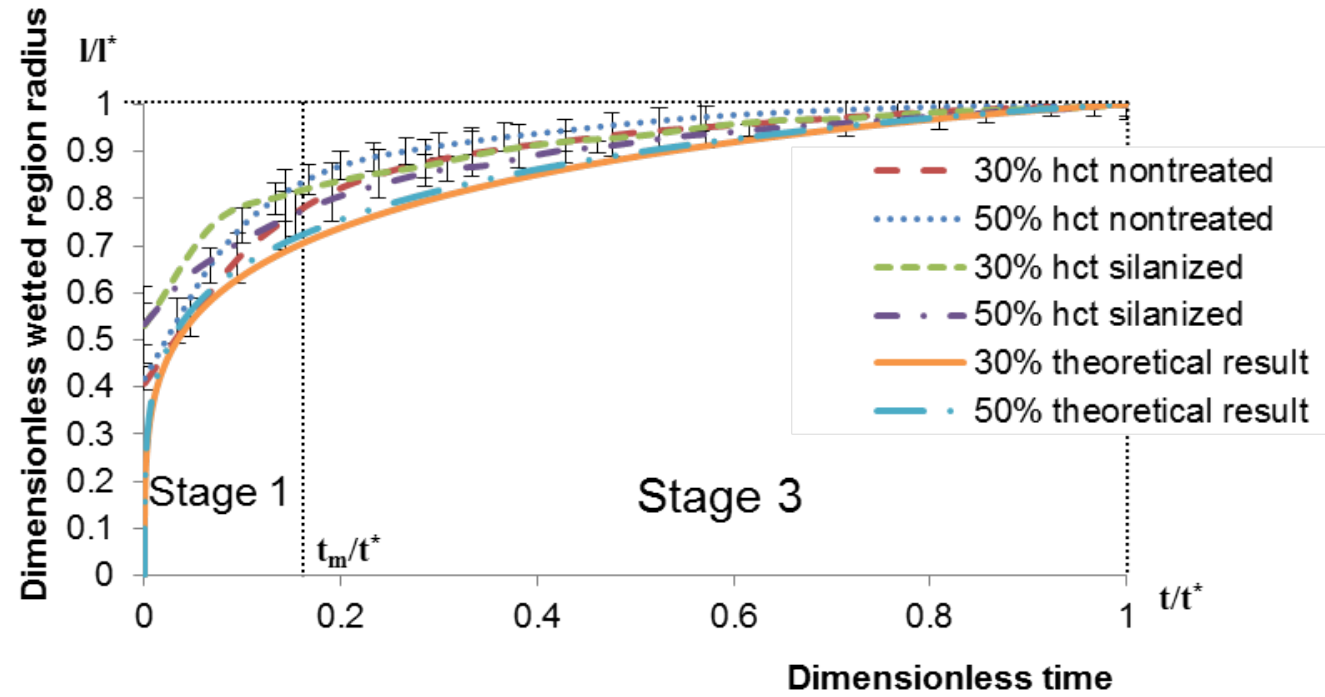

Fig. 12. Dimensionless radius of the wetted region inside the filter paper in the case of spreading over silanized and non-treated Whatman 903 paper. 
Figs. 10-12 prove that the same universal behavior is still valid for more hydrophobic silanized filter paper.

\section{Conclusions}

The spreading behaviour of blood droplets with two different haematocrit levels on different porous substrates has been investigated: nitrocellulose membranes (NCM) of three different pore sizes $0.2,3$ and $8 \mu \mathrm{m}$ and silanized Whatman 903 filter paper. It was shown that blood droplets showed a partial wetting behavior on all NCM. However, in spite of silanization of the Whatman 903 filter paper, the blood droplet showed a complete spreading behavior. The silanization caused a considerable increase in the dynamic contact angle, but the spreading behaviour still remained complete wetting. Our results proved that only plasma and very few RBCs penetrated into the porous membrane in the case of the blood spreading over 0.2 and $3.0 \mu \mathrm{m}$ nitrocellulose membranes. This opens a new possibility of blood sampling, when the RBCs are mostly collected on the membrane surface and almost completely separated from plasma, which is collected inside the membrane pores. Important to emphasize, that in the course of spreading over 0.2 and $3.0 \mu \mathrm{m}$ nitrocellulose membranes the red bold cells were not damaged. This opens a completely new opportunity to (1) investigate RBCs and plasma separately; (2) to use this method for non-destructive separation of living cells from aqueous solutions.

\section{Acknowledgement}

This research was supported by CoWet Marie Curie EU project; the Royal Society, UK; COST action MP1106, EU; European Space Agency projects PASTA and EVAPORATION MAP. 


\section{References}

[1] R.J. Meesters, G.P. Hooff, State-of-the-art dried blood spot analysis: an overview of recent advances and future trends., Bioanalysis. 5 (2013) 2187-208. doi:10.4155/bio.13.175.

[2] J. Henion, R. Oliveira, D. Chace, Microsample analyses via DBS: challenges and opportunities, Bioanalysis. 5 (2013) 2547-65. doi:10.4155/bio.13.197.

[3] P. Denniff, C. Holliman, L. Svensson, N. Weng, S. Patel, Bioanalysis zone: DBS survey results., Bioanalysis. 6 (2014) 287-91. doi:10.4155/bio.13.327.

[4] P. a Demirev, Dried blood spots: analysis and applications., Anal. Chem. 85 (2013) 779-89. doi:10.1021/ac303205m.

[5] W. Li, F.L.S. Tse, Dried blood spot sampling in combination with LC-MS/MS for quantitative analysis of small molecules., Biomed. Chromatogr. 24 (2010) 49-65. doi:10.1002/bmc.1367.

[6] S. Lehmann, C. Delaby, J. Vialaret, J. Ducos, C. Hirtz, Current and future use of "dried blood spot" analyses in clinical chemistry., Clin. Chem. Lab. Med. 51 (2013) 1897-909. doi:10.1515/cclm-2013-0228.

[7] J. Déglon, A. Thomas, P. Mangin, C. Staub, Direct analysis of dried blood spots coupled with mass spectrometry: concepts and biomedical applications., Anal. Bioanal. Chem. 402 (2012) 2485-98. doi:10.1007/s00216-011-5161-6.

[8] B.G. Keevil, The analysis of dried blood spot samples using liquid chromatography tandem mass spectrometry., Clin. Biochem. $44 \quad$ (2011) 110-8. doi:10.1016/j.clinbiochem.2010.06.014.

[9] I.J.M. Snijdewind, J.J. a van Kampen, P.L. a Fraaij, M.E. van der Ende, A.D.M.E. Osterhaus, R. a Gruters, Current and future applications of dried blood spots in viral disease management., Antiviral Res. 93 (2012) 309-21. doi:10.1016/j.antiviral.2011.12.011.

[10] P.M. Edelbroek, J. Van der Heijden, L.M.L. Stolk, Dried blood spot methods in therapeutic drug monitoring: methods, assays, and pitfalls., Ther. Drug Monit. 31 (2009) 327-36. doi:10.1097/FTD.0b013e31819e91ce.

[11] S. Tanna, G. Lawson, Analytical methods used in conjunction with dried blood spots, Anal. Methods. 3 (2011) 1709. doi:10.1039/c1ay05160a.

[12] M. Barfield, N. Spooner, R. Lad, S. Parry, S. Fowles, Application of dried blood spots combined with HPLC-MS/MS for the quantification of acetaminophen in toxicokinetic studies, J. Chromatogr. B. 870 (2008) 32-37. doi:10.1016/j.jchromb.2008.05.025. 
[13] J.E. Burnett, Dried blood spot sampling: practical considerations and recommendation for use with preclinical studies., Bioanalysis. 3 (2011) 1099-107. doi:10.4155/bio.11.68.

[14] V.R. De Jesus, D.H. Chace, Commentary on the history and quantitative nature of filter paper used in blood collection devices, Bioanalysis. 4 (2012) 645-647.

[15] P.W. Smit, I. Elliott, R.W. Peeling, D. Mabey, P.N. Newton, An overview of the clinical use of filter paper in the diagnosis of tropical diseases., Am. J. Trop. Med. Hyg. 90 (2014) 195-210. doi:10.4269/ajtmh.13-0463.

[16] T.C. Chao, O. Arjmandi-Tash, D.B. Das, V.M. Starov, Spreading of blood drops over dry porous substrate: Complete wetting case, J. Colloid Interface Sci. 446 (2015) 218225. doi:10.1016/j.jcis.2015.01.054.

[17] T.C. Chao, A. Trybala, V. Starov, D.B. Das, Influence of haematocrit level on the kinetics of blood spreading on thin porous medium during dried blood spot sampling, Colloids Surfaces A Physicochem. Eng. Asp. 451 (2014) 38-47. doi:10.1016/j.colsurfa.2014.03.033.

[18] P. De Gennes, Wetting: statics and dynamics, Rev. Mod. Phys. 57 (1985). http://rmp.aps.org/abstract/RMP/v57/i3/p827_1 (accessed April 13, 2014).

[19] V. Starov, V. Kalinin, J. Chen, Spreading of liquid drops over dry surfaces, Adv. $\begin{array}{lllll}\text { Colloid } & \text { Interface } & \text { Sci. } & 50 & \text { (1994) }\end{array}$ http://www.sciencedirect.com/science/article/pii/0001868694800308 (accessed October 7, 2014).

[20] T. Blake, J. Haynes, Kinetics of liquidliquid displacement, J. Colloid Interface Sci. 80 (1969) 421-423. http://www.sciencedirect.com/science/article/pii/0021979769904111 (accessed October 7, 2014).

[21] G.F. Teletzke, H. Ted Davis, L.E. Scriven, How Liquids Spread on Solids, Chem. Eng. Commun. 55 (1987) 41-82. doi:10.1080/00986448708911919.

[22] V.M. Starov, a N. Tyatyushkin, M.G. Velarde, S. a Zhdanov, Spreading of nonNewtonian liquids over solid substrates., J. Colloid Interface Sci. 257 (2003) 284-90. http://www.ncbi.nlm.nih.gov/pubmed/16256482.

[23] S. Semenov, A. Trybala, R.G. Rubio, N. Kovalchuk, V. Starov, M.G. Velarde, Simultaneous spreading and evaporation: Recent developments., Adv. Colloid Interface Sci. 206 (2013) 382-398. doi:10.1016/j.cis.2013.08.006.

[24] K. Sefiane, J. Skilling, J. MacGillivray, Contact line motion and dynamic wetting of nanofluid solutions., Adv. Colloid Interface Sci. 138 (2008) 101-20. doi:10.1016/j.cis.2007.12.003.

[25] M. Schmitt, K. Groß, J. Grub, F. Heib, Detailed statistical contact angle analyses; "slow moving" drops on inclining silicon-oxide surfaces., J. Colloid Interface Sci. 447 (2014) 229-239. doi:10.1016/j.jcis.2014.10.047. 
[26] V. Starov, S. Zhdanov, Spreading of liquid drops over porous substrates, Adv. Colloid Interface Sci. 104 (2003) 123-158. doi:10.1016/S0001-8686.

[27] V.M. Starov, S.R. Kosvintsev, V.D. Sobolev, M.G. Velarde, S. a Zhdanov, Spreading of liquid drops over saturated porous layers., J. Colloid Interface Sci. 246 (2002) 3729. doi:10.1006/jcis.2001.8077. 